\title{
Letter from the President
}

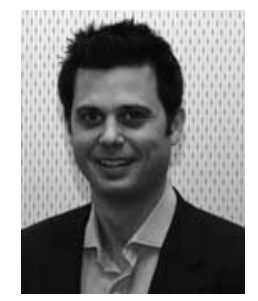

Mark Radford

\section{QUO VADIS II}

This is my last letter to you as President, as I will be stepping down in June of this year at Conference. In this final letter, I feel that I can indulge a little and discuss a subject close to my heart.

I came into nursing in the early 1990s as a young man full of ideas and enthusiasm for my new profession. It was a difficult time for nursing as a whole, with successive cut backs leading to funding problems in the NHS and few jobs available to those new to the profession. In addition, the seismic shift from Hospital based education to the universities was starting to make its mark, and caused profound reaction in the profession. As a newly qualified staff nurse, these changes were minor blips in the professional road, and they would not stop me doing what I set out to do... to nurse patients.

One of the first challenges I came across in these early years of perioperative practice, was the debate around the role of the nurse in theatre. There were continued challenges in the literature and the profession. The issue of nurses and technicians was at its height, and up and down the country, nurses and ODPs were often being re-titled as practitioners. The intention was a good one to bring together roles and responsibilities, pay parity and a sense of collegiate practice in theatres. However, I was profoundly shocked as a nurse as I was justifiably proud of the profession that I had joined and resisted attempts to do this. Those three years of nurse training seemed to be brushed aside, and with it my values and beliefs, as to the core of drive and passion for caring for patients. I looked at my profession and the patients I cared for, and knew instinctively that nursing did offer something unique in the care of these patients and set about my first political campaign (albeit on a local and small scale) to challenge the view that I was a practitioner - I was not, I was a nurse.

Even now, looking back I still feel that this was the right thing to do. I did not do this to denigrate our ODP colleagues who work alongside us caring for patients. They do so caringly and with compassion, but from a different training perspective. The role of the ODP has opened up access to healthcare careers to those for whom general nursing training was not what they wanted. Theatres and PACUs up and down the country are richer for it and their contribution. Nursing does not have the monopoly on care in the NHS, there are plenty that do that, and do it well.

Some may say that this was manifestly professional protectionism or youthful enthusiasm/militancy and that I was just trying to sabotage change within my unit, but I did it out of a belief that this was the right thing to do. On the back of this, I started work to try and get nursing students back into theatre, campaigning with the local university to find a way of re-focussing the curriculum on the care aspects in theatre and the learning opportunities that would come with it. It was hard work, but we got there.

From this work, I joined BARNA back in 1996. It was one of the first steps that I took, to try and work with those organisations that could influence change. It was such a dynamic organisation, rich with talent, 
which seemed to bounce like 'tigger' with conviction and enthusiasm that was infectious on any topic related to Peri-anaesthesia care. It did not care if it had an invite; it muscled in and made its presence felt amongst the leading perioperative associations. Sometimes raising eyebrows amongst the establishment in the process. The great debate at the time was the development of nurse anaesthetist in the UK. The battle lines were drawn against the big political players, and BARNA was there, shaping and influencing the future direction. No conclusions were reached, as argument and counterargument raged over issues of safety, skills and competence. Ultimately, the real decision and change came much later, with the pressure on junior doctor's hours, and political influence from the Department of Health to modernise the NHS. In particular, the workforce development in the NHS gave a clinical career structure that released the potential of people's skills, including many nurses and AHPs. I know that BARNA was influential in that debate; it may have been a small player, but it packed a mighty punch. We may have lost that battle, at that time, but some may debate that the war was ultimately won.

But where is BARNA going in the future? What are the burning issues of the day that exercise you as members? Associations, and their role in professions and the NHS have changed as the landscape of healthcare has moved away from professions being the controlling factor. However, we may have missed a trick. What remains missing from a great deal of our debate is one of the most fundamental power bases for nurses, and now the most important and profound influence on future trends... the patient. It seems odd now to look back all those years at the struggle and my own political activism as it was often more about professional role, terms and conditions rather than this aspect of the role. I see four main issues for nursing for the future to deliver; real public and patient partnership, redefining the 'brand', policy and political activism.

Public choice is a clear agenda in the UK NHS, but mirrors changes globally. With this more commercialised approach to healthcare will come new challenges to see patients as customers rather than in the traditional sick role we saw in patriarchal systems of care. Healthcare regulators will be taking much greater interest in patient experience, including more nursing related issues such as privacy, dignity and compassion. Nurses in the NHS are now as much 'managers of expectation' and customer service staff as much as bedside experts in care. The trick will be to deliver both, and remain a central influence in the healthcare agenda.
That said, nursing still remains in a unique position and there is intrinsic power in the nurse-patient relationship that should be developed; the basis of which should be through nursing intervention and integrated care, rather than the devolvement of medical orders in quasi-medical specialisation of nursing. The drive from both professions for integrated care is clear and has government support. Yet, nursing's approach down the specialised route, taking over more tasks from medical staff, may limit their leadership impact on health. Whilst nurses should develop their portfolio of skills, and this includes diagnosis and investigation, it should not be at the expense of more general nursing capability and care delivery. Rather than sub specialise as practitioners, nursing should diversify and generalise its practice base with advanced and specialist skills to offer greater care continuity in these services.

Nursing often has an image problem with its customer. Media have exposed a number of failings of care, and public perception of nursing is poor globally. Though some commentators suggest that this may have been ignored by nursing for some time, as it concentrated upon bettering its terms and conditions. The 'brand' of nursing needs to be simplified. The significant diversity and complexity of role and responsibility has fragmented the brand, which has resulted in a significant challenge for nursing leaders to address. How would you represent the diverse nature of nursing in modern healthcare? Specialisation of nursing will remain a real market force, reflecting changes in global healthcare - however, if the nursing profession wishes to remain an influential partner in care then action is required.

The last twenty years in the UK NHS has seen an unprecedented level of policy directed at nursing to fulfil its potential as leaders in the health market, but often has failed to fully capitalise on this. There have been some successes and generally a move forward for nursing politically during this time. Influencing policy will be one effective arm of the strategy to develop nursing leadership, and can take many lessons from the commercial world to help deliver. This will go some way to challenge the perceptions of being done to as a profession. Nursing leadership simply has not made the connection that they could actively shape policy, bridging the policy/practice divide.

Part of the issue for nursing is its lack of political activism and this needs to be addressed by its future leaders. However, this can only come through determined understanding of the definition of what nursing now is, and the role they are to play in healthcare. This cannot take place where nurse's intrinsic power base is 
determined by their proximity in skills and intellect to Doctors - that is for the sociologists to debate and discuss. Nursing should 'Let go of the legacy' defining itself as the 'martyr' or victim of organisational and political culture, and set about defining itself as the advocate and choice of patients to deliver their care needs.

Political activism can take many forms, and those issues that we take up should be based upon the needs and issues of patients, not those of nurses. The central issues for patients for the future will centre around choice, access, quality, experience, equity and human rights. Look to our American PACU colleagues in California, and the battle they won staffing levels and care quality.

Utilising dynamic leadership models will enable nursing to galvanise the large professional support base of nurses in the UK around common themes to deliver change in healthcare, something that has eluded nursing to its cost.

In my view, associations are more important than ever to bring together, galvanise and start the process of engagement for greater influence of the decisions that affect the patients that we care for. However, an association is its membership... . You are the people to take this forward and make the difference.

I know that BARNA is still a thriving and dynamic association, and it has been an honour to be your president. I thank you all as members for the way you have supported the association for the last twenty-three years. You have done it with pride, passion and a sense of fun.

Good Luck Mark Radford 